\title{
MODELAGEM DO PROCESSO DE SECAGEM DE SEMENTES DE FEIJÃO-CAUPI ${ }^{1}$
}

\author{
RAFAELA GREICI DA MOTTA CAMICIA ${ }^{2 *}$, DIVAIR CHRIST ${ }^{3}$, SILVIA RENATA MACHADO COELHO ${ }^{3}$, \\ RICARDO FERNANDO DA MOTTA CAMICIA ${ }^{4}$
}

\begin{abstract}
RESUMO - O trabalho teve como objetivo modelar curvas de secagem do feijão-caupi (Vigna unguiculata (L.) Walp.) em diferentes temperaturas, determinar o coeficiente de difusão efetivo e a energia de ativação. Para isso, utilizou-se sementes de feijão-caupi, cultivar BRS guariba, colhidas manualmente, com teor de água de $21 \%$ (base úmida) e secas até o teor de água de $11 \%$ (base úmida). A secagem foi realizada em secador experimental sob temperaturas controladas de 30,40 e $50{ }^{\circ} \mathrm{C} \pm 1{ }^{\circ} \mathrm{C}$ e umidade relativa do ar de secagem entre 14 e 59\%. Foram testados 12 modelos de regressão não-linear e para a seleção do melhor modelo considerou-se a significância do coeficiente de regressão pelo teste $t$, a magnitude do coeficiente de determinação ajustado $\left(\mathrm{R}^{2}\right)$, o erro médio relativo $(\mathrm{P})$ e o erro médio estimado (SE). Observou-se que o tempo de secagem para as sementes de feijão-caupi foi de $10,4,5,6$, e $2,1 \mathrm{~h}$ para as temperaturas de 30,40 e $50{ }^{\circ} \mathrm{C}$, respectivamente. Dentre a série testada, o modelo matemático de Midilli foi o que melhor se ajustou aos dados experimentais. O coeficiente de difusão aumenta com a elevação da temperatura, apresentando valores entre $5,047 \times 10^{-11}$ a $12,011 \times 10^{-11} \mathrm{~m}^{2} \mathrm{~s}^{-1}$ para a faixa de temperatura de 30 a $50{ }^{\circ} \mathrm{C}$. A relação entre o coeficiente de difusão efetivo e a temperatura de secagem podem ser descritas pela equação de Arrhenius, que apresenta uma energia de ativação de $35,04 \mathrm{~kJ}$ $\mathrm{mol}^{-1}$ para a difusão líquida no processo de secagem das sementes de feijão-caupi.
\end{abstract}

Palavras-chave: Vigna unguiculata (L.) Walp. Curvas de secagem. Coeficiente de difusão.

\section{MODELING OF THE DRYING PROCESS THE SEEDS OF COWPEA}

\begin{abstract}
The study aimed to model the drying curves of cowpea beans (Vigna unguiculata (L.) Walp.) in different temperatures determine the coefficient of effective diffusion and the activation energy. For this, we used seeds of beans-cowpea cultivar BRS Guariba, harvested manually, with a water content of $21 \%$ (wet basis), dried until the water content $11 \%$ (wet basis). Drying was performed in the experimental dryer under controlled temperatures of 30,40 and $50{ }^{\circ} \mathrm{C} \pm 1{ }^{\circ} \mathrm{C}$, and relative humidity of the air drying between 14 and $59 \%$. 12 models of non-linear regression were tested and for selection the best model was considered to: the significance of the regression coefficient $t$ test, the magnitude of the adjusted coefficient of determination $\left(\mathrm{R}^{2}\right)$, the average relative error $(\mathrm{P})$ and the estimated average error $(\mathrm{SE})$. It was observed that the drying time for of the beans-cowpea seeds was 10,$4 ; 5,6$; and $2,1 \mathrm{~h}$ to the temperatures of 30,40 and $50{ }^{\circ} \mathrm{C}$, respectively; among the number tested, the mathematical model the Midilli was the best fit to experimental data. The coefficient of diffusion increases with temperature, with values between $5,047 \times 10^{-11}$ to $12,011 \times 10^{-11} \mathrm{~m}^{2} \mathrm{~s}^{-1}$ for the temperature range from 30 to $50{ }^{\circ} \mathrm{C}$. The relationship between the coefficient of diffusion effective and the drying temperature can be described by Arrhenius equation, which presents activation energy of $35,04 \mathrm{~kJ} \mathrm{~mol}^{-1}$ for spreading the liquid in the drying process of the of beans-cowpea seeds.
\end{abstract}

Keywords: Vigna unguiculata L. Walp. Drying curves. Diffusion coefficient.

\footnotetext{
*Autor para correspondência

${ }^{1}$ Recebido para publicação em 29/07/2014; aceito em 09/02/2015.

Parte da Dissertação do primeiro autor.

${ }^{2}$ Pós-Graduanda em Engenharia Agrícola, Doutorado, Programa de Pós-Graduação em Engenharia Agrícola - Sistemas Biológicos Agroindustriais, UNIOESTE, 85819-110, Cascavel (PR); rafaelacamicia@utfpr.edu.br.

${ }^{3}$ Programa de Pós-Graduação em Engenharia Agrícola - Sistemas Biológicos Agroindustriais, UNIOESTE, 85819-110, Cascavel (PR); divair.christ@unioeste.br, silvia.coelho@unioeste.br.

${ }^{4}$ Engenheiro Agrônomo, Agro Granja Planejamento Agrícola, 85770-000, Realeza (PR); ricardo_camicia@hotmail.com.
} 


\section{INTRODUÇÃO}

O feijão-caupi (Vigna unguiculata L. Walp.) é conhecido popularmente como feijão-de-corda, feijão-miúdo, feijão-macassar e feijão-fradinho (grãos brancos) (BORÉM; CARNEIRO, 2006). É uma cultura tradicionalmente cultivada no Nordeste brasileiro e que vem se expandindo para outras regiões do Brasil em razão de sua ampla adaptabilidade às condições tropicais e ao baixo custo de produção. Fatores como produção de alta qualidade, valor nutritivo e regularidade da oferta em termos de quantidade e padronização do produto têm despertado o interesse de comerciantes, da agroindústria e de distribuidores por essa cultura, colaborando para a abertura de importantes mercados, inclusive no exterior (FREIRE FILHO et al., 2011).

A comercialização de sementes de feijãocaupi exige conhecimentos sobre o armazenamento e cuidados na secagem. A secagem dos produtos é o processo mais utilizado para assegurar a sua qualidade e estabilidade, considerando que a diminuição da quantidade de água do material reduz a atividade biológica e as mudanças químicas e físicas que ocorrem durante o armazenamento (CORRÊA et al., 2007). Desta forma, no desenvolvimento e aperfeiçoamento de equipamentos utilizados para a secagem de grãos e sementes é de fundamental importância a simulação e a obtenção de informações teóricas a respeito do comportamento de cada produto durante a remoção de água (BERBET et al.,1995). Para a simulação, cujo princípio se fundamenta na secagem dos tecidos, são utilizados modelos matemáticos que representam satisfatoriamente a perda do teor de água do produto durante o período de secagem (GONELI et al., 2014; SANTOS et al., 2013).

Os modelos de cálculo da cinética de secagem são aplicados de modo diferente, dependendo do período considerado (MORAIS, 2010). Na literatura, vários modelos foram propostos para analisar a secagem de produtos higroscópicos, quais sejam: teóricos, semiempíricos e empíricos (MARTINAZZO et al., 2007). Entre os modelos semiteóricos, o modelo de Dois Termos, o de Henderson e Pabis, o de Page e o de Page Modificado e Midilli têm sido amplamente utilizados (SIQUEIRA et al., 2013).

Os modelos teóricos que descrevem a taxa decrescente de secagem de um sólido consideram geralmente como mecanismo principal a difusão baseada na segunda Lei de Fick, a qual expressa o fluxo de massa por unidade de área que é proporcional ao gradiente de concentração de água (PARK et al., 2002; ROMERA-PEÑA; KIECKBUSCH, 2003).

$\mathrm{O}$ coeficiente de difusão $\left(\mathrm{D}_{\mathrm{ef}}\right)$ é uma difusividade efetiva que engloba os efeitos de todos os fenômenos que podem intervir sobre a migração da água e seu valor é obtido pelo ajuste de valores experimentais. Todavia, pode-se entender a difusividade como a facilidade com que a água é removida do material (REIS et al., 2011).
O coeficiente de difusão é uma difusividade efetiva que engloba os efeitos de todos os fenômenos, podendo intervir sobre a migração da água e o seu valor é sempre obtido pelo ajuste das curvas experimentais (BROOKER et al., 1992).

Vários trabalhos já foram desenvolvidos para avaliar a secagem de diversos tipos de grãos e sementes. Corrêa et al. (2007), com a secagem de grãos de feijão (Phaseolus vulgaris L.), Costa et al. (2011), ao analisarem o coeficiente de difusão efetivo e modelagem matemática da secagem de sementes de crambe (Crambe abyssinica), Reis et al. (2011), com a secagem de pimenta cumari do Pará, e Diógenes et al. (2013), ao investigarem a cinética de secagem de grãos de abóbora.

Nesse sentido, o objetivo do presente trabalho foi estudar o ajuste de curvas de secagem de sementes de feijão-caupi às temperaturas de 30,40 e $50{ }^{\circ} \mathrm{C}$, como também estimar o coeficiente de difusividade efetiva $\left(D_{e f}\right)$ e a energia de ativação $\left(E_{a}\right)$.

\section{MATERIAL E MÉTODOS}

O cultivo de feijão-caupi foi realizado no município de Capanema, situado no sudoeste do Paraná, com coordenadas geográficas centrais de longitude $53^{\circ} 48^{\prime} 32^{\prime \prime} \mathrm{O}$ e latitude $25^{\circ} 40^{\prime} 19^{\prime \prime} \mathrm{S}$ e elevação média de $368 \mathrm{~m}$, utilizando-se sementes da cultivar BRS Guariba, cedidas pela Embrapa Meio-Norte, Teresina (PI), safra 2010/2011.

A região de plantio é caracterizada por um clima subtropical úmido, mesotérmico, com verões quentes e invernos amenos, sendo pouco frequentes as geadas. As chuvas concentram-se nos meses de verão e não há estação seca definida. A temperatura média é superior a $22{ }^{\circ} \mathrm{C}$ no verão e fica em torno de $18{ }^{\circ} \mathrm{C}$ no inverno (IBGE, 2012). A precipitação pluviométrica durante o plantio foi de $575 \mathrm{~mm}$ (dados da estação meteorológica da usina Salto Caxias-Salto do Lontra).

A colheita do feijão-caupi foi manual, por meio de arranque das vagens e posterior debulha. As amostras com teor de água de $21 \%$ (base úmida) foram submetidas ao processo de limpeza e armazenadas em sacos plásticos, lacrados e acondicionados por seis dias em refrigerador à temperatura de $4{ }^{\circ} \mathrm{C}$.

A secagem foi realizada no Laboratório de Armazenagem e Protótipos de Instalações de Secagem (LAPIS), do Curso de Engenharia Agrícola, na Universidade Estadual do Oeste do Paraná, Campus Cascavel. Previamente aos experimentos de secagem as amostras de feijão-caupi foram retiradas do refrigerador a $4{ }^{\circ} \mathrm{C}$, mantendo-as em temperatura ambiente, visando a sua homogeneização. Para determinação do teor de água inicial foram utilizadas duas subamostras do produto com aproximadamente $5 \mathrm{~g}$ cada. As sementes foram dispostas em cápsulas de alumínio e levadas a estufa a $105^{\circ} \mathrm{C} \pm 3{ }^{\circ} \mathrm{C}$, durante 24 h, com três repetições. Posteriormente, acondicio- 
nadas no dessecador por aproximadamente $20 \mathrm{~min}$ e pesadas para o cálculo do teor de água. Os resultados foram expressos em porcentagem, conforme as Regras para Análises de Sementes (BRASIL, 2009).

Para a secagem do produto foram utilizadas temperaturas de 30,40 e $50{ }^{\circ} \mathrm{C} \pm 1{ }^{\circ} \mathrm{C}$ em um secador de camada fixa em escala de laboratório, com ventilador de fluxo axial. As amostras foram colocadas em três bandejas de metal perfuradas para permitir a passagem do ar através da massa do produto, com o fluxo de ar perpendicular às sementes de feijão-caupi. A velocidade do ar foi monitorada com os auxílios de anemômetro, psicrômetro e termopares do tipo $\mathrm{T}$, respectivamente, sendo que estes valores variaram entre 0,73 a $0,78 \mathrm{~m} \mathrm{~s}^{-1}$.
Durante o processo de secagem foram realizadas pesagens sucessivas das bandejas com as amostras objetivando a determinação do teor de água e o conteúdo adimensional de umidade, utilizando-se balança de precisão $(1 \mathrm{mg})$. A secagem das sementes prosseguiu até que o produto atingisse o teor de água de aproximadamente $11 \%$ (base úmida).

Os dados experimentais de secagem do feijãocaupi foram ajustados aos modelos matemáticos frequentemente utilizados para representação da secagem de produtos agrícolas (AFONSO JÚNIOR; CORRÊA, 1999; AKPINAR et al., 2003; SANTOS et al., 2013; DIÓGENES et al., 2013), cujas expressões estão apresentadas na Tabela 1.

Tabela 1. Modelos de regressão não-linear utilizados para predizer o fenômeno de secagem em camada delgada de sementes de feijão-caupi (Vigna unguiculata (L.) Walp.).

\begin{tabular}{llc}
\hline Modelo & Modelo & Equação \\
\hline Page & $R U=\exp \left(-k \cdot t^{n}\right)$ \\
Henderson e Pabis & $R U=a \cdot \exp (-k \cdot t)$ \\
Midilli & $R U=a \cdot \exp \left(-k \cdot t^{n}\right)+b \cdot t$ \\
Wang e Sing & $R U=1+a \cdot t+b t^{2}$ \\
Thompson & $R U=a \cdot \ln (R U)+b \cdot[\ln (R U)]^{2}$ \\
Page modificado & $R U=\exp \left[-(k \cdot t)^{n}\right]$ \\
Newton & $R U=\exp (-k \cdot t)$ \\
Logarítmico & $R U=a \cdot \exp (-k . t)+c$ \\
Henderson e Pabis, modificado & $R U=a \cdot \exp (-k \cdot t)+b \cdot \exp \left(-k_{0} \cdot t\right)+c \cdot \exp \left(-k_{1} . t\right)$ \\
Exponencial de Dois Termos & $R U=a \cdot \exp (-k \cdot t)+(1-a) \exp (-k \cdot a \cdot t)$ \\
Modelo de dois termos & $R U=a \cdot \exp \left(-k_{0} \cdot t\right)+b \cdot \exp \left(-k_{1} \cdot t\right)$ \\
Modelo de aproximação da difusão & $R U=a \cdot \exp (-k . t)+(1-a) \exp (-k \cdot b . t)$ \\
\hline
\end{tabular}

Fonte: Madamba et al. (1996), Doymaz (2004), Mohapatra e Rao (2005); RU = razão de umidade do produto, adimensional; $\mathrm{t}=$ tempo de secagem, $\mathrm{h} ; \mathrm{k}, \mathrm{k}_{0}, \mathrm{k}_{1}=$ coeficientes de secagem, $\mathrm{h}^{-1} ; \mathrm{e} \mathrm{a}, \mathrm{b}, \mathrm{c}, \mathrm{n}=$ coeficientes dos modelos.

Para a determinação das razões de umidade (RU) do feijão-caupi nas diferentes condições de secagem utilizou-se a Equação 13.

$$
R U=\frac{U-U_{e}}{U_{i}-U_{e}}
$$

em que:

$\mathrm{U}=$ teor de água do produto, decimal base seca;

$\mathrm{U}_{\mathrm{i}}=$ teor de água inicial do produto, decimal base seca;

$\mathrm{U}_{\mathrm{e}}=$ teor de água de equilíbrio do produto, decimal base seca.

Para o ajuste dos modelos matemáticos de secagem aos dados experimentais fora realizado a análise de regressão não-linear pelo método Quasi Newton, utilizando-se o software Statistica 7.0.

Na seleção do melhor modelo foram conside- rados: a significância do coeficiente de regressão pelo teste t, adotando-se o nível de até $5 \%$ de probabilidade; a magnitude do coeficiente de determinação ajustado $\left(\mathrm{R}^{2}\right)$; o erro médio relativo $(\mathrm{P})$; e o erro médio estimado (SE) (SANTOS et al., 2013; RESENDE; FERREIRA; ALMEIDA, 2010, MORAIS, 2010, CORRÊA et al., 2007).

Os erros médios relativo e estimado foram calculados conforme descrito nas Equações 14 e 15 (CORRÊA et al., 2007, RESENDE et al., 2005, RESENDE; FERREIRA; ALMEIDA, 2010), respectivamente:

$$
P=\frac{100}{n} \sum_{i=1}^{n}\left(\frac{|Y-\hat{Y}|}{Y}\right)
$$




$$
S E=\sqrt{\frac{\sum\left(Y-Y_{0}\right)^{2}}{G L R}}
$$

em que:

$\mathrm{Y}=$ valor observado experimentalmente;

$\mathrm{Y}_{0}=$ valor calculado pelo modelo;

GLR = graus de liberdade do modelo (número de observações menos o número de parâmetros do modelo).

O coeficiente de difusão efetivo foi obtido por meio do ajuste do modelo matemático da difusão líquida, descrito pela Equação 16, aos dados experimentais da secagem das sementes de feijão-caupi. Essa equação é a solução analítica para a segunda lei de Fick, considerando a forma geométrica do produto como esférica, desconsiderando a contração volumétrica dos grãos e considerando a condição de contorno de teor de água conhecida na superfície do grão (BROOKER et al., 1992).

$R U=\frac{U-U_{e}}{U_{i}-U_{e}}=\frac{6}{\pi^{2}} \sum_{n=1}^{\infty} \frac{1}{n^{2}} \exp \frac{n^{2} \pi^{2} D_{e f} t}{r^{2}}$

em que:

Def = coeficiente de difusão efetivo $\left(\mathrm{m}^{2} \mathrm{~s}^{-1}\right)$;

$\mathrm{r}=$ raio equivalente, $\mathrm{m}$;

$\mathrm{n}=$ número de termos;

$\mathrm{t}=$ tempo,s.

O raio equivalente, utilizado no modelo da difusão, é definido como o raio de uma esfera cujo volume é igual ao do grão, sendo determinado por meio da medição dos três eixos ortogonais (comprimento, largura e espessura) com o auxílio de um paquímetro digital (precisão de $0,001 \mathrm{~mm}$ ). $\mathrm{O}$ volume de cada grão (V), considerado como um esferoide triaxial, foi obtido utilizando-se a seguinte expressão (REIS, 2011; COSTA et al., 2011):

$$
V=\frac{\pi(a \cdot b \cdot c)}{6}=\frac{4 \pi \cdot r^{3}}{3}
$$

em que:

$\mathrm{V}=$ volume do grão, $\mathrm{mm}^{3}$;

$\mathrm{a}=$ maior eixo do grão (comprimento), $\mathrm{mm}$;

$\mathrm{b}=$ eixo médio do grão (largura), $\mathrm{mm}$;

$\mathrm{c}=$ menor eixo do grão (espessura), $\mathrm{mm}$.

A variação do coeficiente de difusão, de acordo com a temperatura de secagem, foi analisado utilizando a relação de Arrhenius (Equação 18):

$$
D=A \exp \left(-\frac{E}{R T}\right)
$$

em que:

$\mathrm{A}=$ constante $\left(\mathrm{m}^{2} \mathrm{~s}^{-1}\right)$

$\mathrm{E}=$ energia de ativação $\left(\mathrm{J} \mathrm{mol}^{-1}\right)$;

$\mathrm{R}=$ constante universal dos gases $\left(8,314 \mathrm{~J} \mathrm{~mol}^{-1} \mathrm{~K}^{-}\right.$

$\left.{ }^{1}\right)$;

$\mathrm{T}=$ temperatura absoluta $(\mathrm{K})$.

\section{RESULTADOS E DISCUSSÃO}

No processo de determinação das curvas de secagem o teor de água inicial das sementes de feijão -caupi foi de $21 \pm 0,2 \%$ (base úmida). A umidade relativa do ar de secagem foi de 59,35 e $14 \%$, respectivamente, para as temperaturas de 30,40 e $50^{\circ}$ $\mathrm{C}$, durante o processo de dessorção das sementes. Analisando-se a Figura 1 observa-se que o tempo necessário para o feijão-caupi atingir o teor de água de aproximadamente $11 \%$ (base úmida) foi de 10,4 , 5,6 e $2,1 \mathrm{~h}$ para as temperaturas de 30,40 e $50^{\circ} \mathrm{C}$, respectivamente.

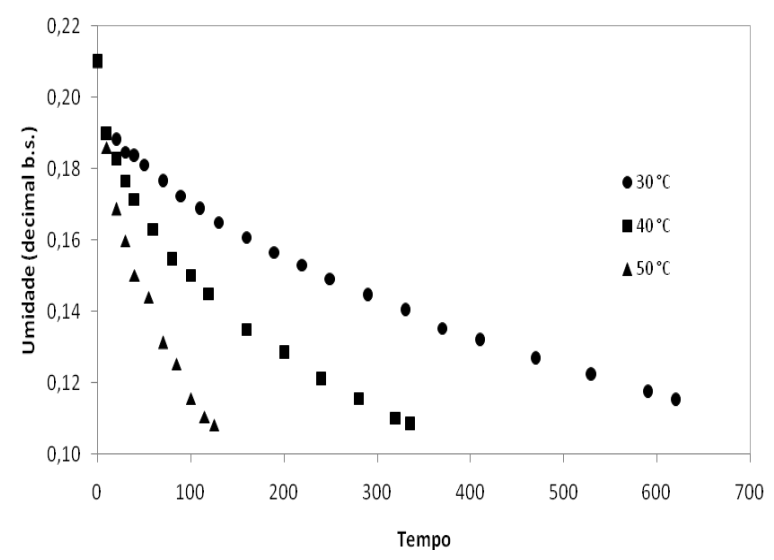

Figura 1. Valores médios da razão de umidade (decimal) em relação ao tempo de secagem (min) para as condições de temperatura de 30,40 e $50{ }^{\circ} \mathrm{C}$ durante a secagem do feijão-caupi (Vigna unguiculata (L.) Walp.).

Não foi possível observar o período de taxa de secagem constante para as condições estudadas, verificando-se que a secagem das sementes ocorre no período de taxa decrescente. Estes resultados estão de acordo com os trabalhos realizados sobre a secagem de produtos, como folhas de manjericão (REIS et al., 2012), feijão vermelho e preto (RESENDE et al., 2008) e, trigo (MOHAPATRA; RAO, 2005).

Com o aumento da temperatura do ar de secagem ocorreu maior taxa de remoção de água do produto, concordando com diversos pesquisadores para vários produtos agrícolas (SANTOS et al, 2014 (grãos de urucum); AKPINAR et al., 2003 (pimenta vermelha); AZZOUZ et al., 2002 (uva); BASUNIA; 
ABE, 2001 (café); KAYMAK-ERTEKIN, 2002 (pimentão verde e vermelho); YALDIZ et al., 2001 (uva)).

Para a comparação entre os modelos de secagem analisados são apresentados na Tabela 2 os va- lores dos parâmetros estatísticos coeficientes de determinação $\left(\mathrm{R}^{2}\right)$ e os erros médios relativo $(\mathrm{P})$ e estimado (SE) para os modelos ajustados de secagem do feijão-caupi, nas temperaturas de 30,40 e $50^{\circ} \mathrm{C}$.

Tabela 2. Coeficientes de determinação $\left(\mathrm{R}^{2}, \%\right)$, erros médio relativo $(\mathrm{P}, \%)$ e estimado (SE, decimal) para os modelos analisados durante a secagem do feijão-caupi (Vigna unguiculata (L.) Walp.), cultivar BRS guariba, em diferentes condições de temperatura $\left({ }^{\circ} \mathrm{C}\right)$.

\begin{tabular}{llllllllll}
\hline \multirow{2}{*}{ Modelo } & \multicolumn{4}{c}{$30^{\circ} \mathrm{C}$} & \multicolumn{3}{c}{$40^{\circ} \mathrm{C}$} & & \multicolumn{3}{c}{$50^{\circ} \mathrm{C}$} \\
\cline { 2 - 10 } & $\mathrm{R}^{2}$ & $\mathrm{P}$ & $\mathrm{SE}$ & $\mathrm{R}^{2}$ & $\mathrm{P}$ & $\mathrm{SE}$ & $\mathrm{R}^{2}$ & $\mathrm{P}$ & $\mathrm{SE}$ \\
\hline Page & 97,36 & 13,79 & 0,041 & 99,72 & 2,11 & 0,011 & 99,22 & 3,39 & 0,018 \\
Henderson e Pabis & 96,90 & 8,48 & 0,040 & 95,78 & 6,86 & 0,046 & 96,07 & 6,03 & 0,042 \\
Midilli & 99,27 & 6,40 & 0,020 & 99,83 & 1,17 & 0,096 & 99,23 & 3,39 & 0,018 \\
Wang e Sing & 95,96 & 18,45 & 0,100 & 96,05 & 11,54 & 0,072 & 96,85 & 7,13 & 0,044 \\
Thompson & 96,02 & 23,61 & 0,059 & 98,84 & 6,47 & 0,031 & 97,33 & 7,21 & 0,041 \\
Page modificado & 97,36 & 13,79 & 0,041 & 99,72 & 2,11 & 0,011 & 99,22 & 3,39 & 0,018 \\
Newton & 96,73 & 15,63 & 0,081 & 96,90 & 15,18 & 0,081 & 96,70 & 9,35 & 0,057 \\
Logarítmico & 96,87 & 8,59 & 0,040 & 98,10 & 4,68 & 0,030 & 98,43 & 4,56 & 0,026 \\
Henderson e Pabis modificado & 99,37 & 7,55 & 0,019 & 98,99 & 3,89 & 0,022 & 98,67 & 3,74 & 0,024 \\
Exponencial de dois termos & 97,44 & 10,89 & 0,058 & 98,51 & 9,35 & 0,050 & 98,54 & 5,00 & 0,032 \\
Dois termos & 99,37 & 7,55 & 0,019 & 99,67 & 2,31 & 0,012 & 99,30 & 3,27 & 0,017 \\
Aproximação da difusão & 99,37 & 7,55 & 0,019 & 98,99 & 3,88 & 0,022 & 98,67 & 3,74 & 0,024 \\
\hline
\end{tabular}

Considerando-se as diferentes condições de secagem para o feijão-caupi, verificou-se nos modelos matemáticos ajustados aos dados experimentais coeficientes de determinação $\left(\mathrm{R}^{2}\right)$ superiores a $90 \%$, indicando, de acordo com Mohapatra e Rao (2005), uma representação satisfatória do processo de secagem, sendo os modelos de Midilli, Henderson e Pabis modificado, Dois Termos e aproximação da difusão os que possuem os maiores valores do coeficiente de determinação $\left(\mathrm{R}^{2}\right)$ em todas as temperaturas de secagem estudadas.

O coeficiente de determinação isoladamente não constitui um bom parâmetro para a seleção de modelos não-lineares. Desta forma, utiliza-se os valores dos erros médio relativo (P) e estimado (SE) (MADAMBA, et al., 1996).

Analisando-se os valores do erro médio estimado, nota-se que nas temperaturas em estudo, o modelo de Midilli apresentou o menor valor, seguido do modelo de Dois Termos. Na modelagem da secagem do feijão vermelho Corrêa et al. (2007) também observaram resultados semelhantes para os dois modelos. Destaca-se nos modelos de Midilli e Dois Termos os melhores valores do erro médio relativo, sendo inferiores a $10 \%$ (Tabela 2), que de acordo com Mohapatra e Rao (2005) indica uma representação adequada do fenômeno.

Dessa forma, os modelos de Midilli e Dois Termos obtiveram os melhores ajustes aos dados experimentais da secagem do feijão-caupi. Ambos os modelos apresentam comportamentos e resultados semelhantes, mas neste estudo selecionou-se o modelo matemático de Midilli para representar a cinética da secagem do feijão-caupi, por apresentar operações matemáticas simples e ser frequentemente recomendado e aplicado para predizer o processo de secagem de produtos agrícolas, concordando com os resultados verificados por Goyalde et al. (2009) para a modelagem matemática da secagem da cana-deaçúcar, Reis et al. (2011) com o trabalho de modelagem da secagem dos frutos da pimenta cumari do Pará e Meneghetti et al. (2012) na secagem de grãos de arroz.

A Figura 2 apresenta as curvas de secagem do feijão-caupi, experimentais e estimadas, pelo modelo de Midilli em função do tempo (minutos) de secagem para as temperaturas de 30,40 e $50{ }^{\circ} \mathrm{C}$. Verificou-se, pela correspondência entre os valores experimentais e estimados, ajuste satisfatório do modelo para a descrição da secagem do feijão-caupi na cultivar em estudo.

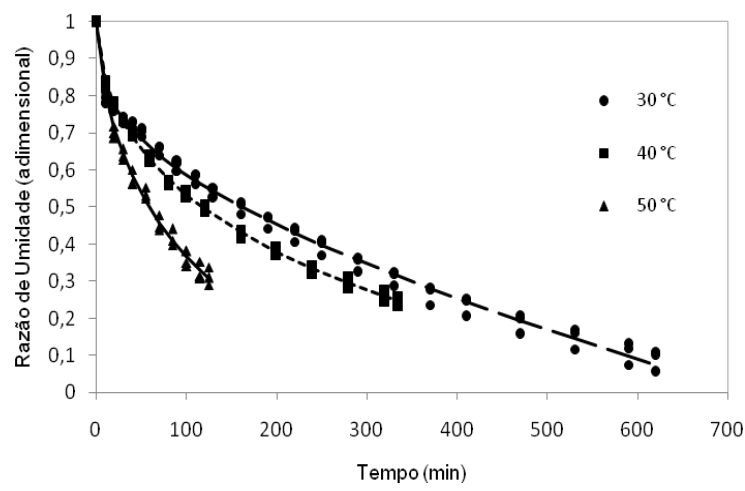

Figura 2. Valores experimentais da razão de umidade (RU, decimal) e estimados pelo modelo de Midilli para a secagem do feijão-caupi (Vigna unguiculata (L.) Walp.) nas diferentes condições de temperatura.

$\mathrm{Na}$ Tabela 3 estão apresentados os coeficientes do modelo de Midilli ajustados em função da temperatura para a secagem do feijão-caupi nas temperaturas de 30,40 e $50^{\circ} \mathrm{C}$ e diferentes condições de umidade relativa do ar de secagem. 
R. G. M. CAMICIA et al.

Tabela 3. Coeficientes do modelo de Midilli durante a secagem do feijão-caupi (Vigna unguiculata (L.) Walp.) para as temperaturas de 30,40 e $50{ }^{\circ} \mathrm{C}$ e umidade relativa do ar variando de 14 a $59 \%$.

\begin{tabular}{|c|c|c|c|c|}
\hline \multirow{2}{*}{ Coeficientes } & \multicolumn{3}{|c|}{ Temperatura $\left({ }^{\circ} \mathrm{C}\right)$} & \multirow[b]{2}{*}{ Equação } \\
\hline & 30 & 40 & 50 & \\
\hline A & $0,9931 *$ & $0,9985 *$ & $1,0015^{*}$ & $a=-110^{-05} \cdot T^{2}+0,0014 \cdot T+0,9625$ \\
\hline $\mathrm{K}$ & $0,00743^{*}$ & $0,0481 *$ & $0,0465^{*}$ & $k=-0,0002 \cdot T^{2}+0,0189 \cdot T-0,3682$ \\
\hline $\mathrm{N}$ & $0,38844 *$ & $0,5426^{*}$ & $0,6549^{*}$ & $\mathrm{n}=-0,0002 \cdot \mathrm{T}^{2}+0,0301 \cdot T-0,3252$ \\
\hline $\mathrm{B}$ & $-0,0005^{*}$ & $-0,0002 *$ & $-0,0002 *$ & $b=-210^{-06} \cdot T^{2}+0,0001 \cdot T-0,0032$ \\
\hline
\end{tabular}

$*$ = significativos a $5 \%$ de probabilidade, pelo teste $\mathrm{t}$.

Analisando os resultados da Tabela 3 tem-se que as magnitudes dos coeficientes "a", "k", " $n$ " e "b" para o modelo de Midilli ajustaram-se ao modelo quadrático com a elevação da temperatura do ar de secagem. Observa-se que a constante (a) aumentou com o aumento da temperatura, e (b) e (n) não apresentaram uma tendência clara em função do aumento da temperatura de secagem. Já a constante de secagem (k) para o modelo de Midilli diminuiu com o aumento da temperatura. Resultado semelhante observou Martinazzo et al. (2007) na modelagem matemática da descrição do processo secagem de feijão vermelho.

Em virtude do mecanismo de transporte da água no interior do produto ocorrer por meio de difusão de vapor utilizou-se a equação baseada na Lei de Fick, com oito termos para produtos com forma geométrica esférica, para calcular a partir dos dados experimentais a difusividade efetiva do produto $\left(D_{\text {ef }}\right)$.

$\mathrm{Na}$ Tabela 4 estão os valores do coeficiente de difusão efetivo das sementes de feijão-caupi para cada condição de secagem. Utilizou-se o raio equivalente $0,0037 \mathrm{~m}$, os quais os dados foram obtidos pelo ajuste da equação 16 aos dados experimentais de secagem de feijão-caupi, com aproximação de oito termos, a partir do qual se observou que o valor de $\mathrm{D}_{\mathrm{ef}}$ não variava.

Tabela 4. Valores da difusividade efetiva $\left(\mathrm{D}_{\mathrm{ef}}\right)$ obtidos para o feijão-caupi (Vigna unguiculata (L.) Walp.) em diferentes temperaturas do ar de secagem.

\begin{tabular}{ccc}
\hline $\begin{array}{c}\text { Temperatura } \\
\left({ }^{\circ} \mathrm{C}\right)\end{array}$ & $\begin{array}{c}\mathrm{D}_{\mathrm{ef}} \\
\left(10^{-11} \mathrm{~m}^{2} \mathrm{~s}^{-1}\right)\end{array}$ & $\begin{array}{c}\mathrm{R}^{2} \\
(\%)\end{array}$ \\
\hline 30 & 5,047 & 98,90 \\
40 & 6,047 & 99,59 \\
50 & 12,011 & 98,88 \\
\hline
\end{tabular}

Os valores da difusividade das sementes de feijão-caupi aumentaram com a elevação da temperatura de secagem, com valores de 5,047 x $10^{-11} \mathrm{~m}^{2} \mathrm{~s}^{-1}$, $6,047 \times 10^{-11} \mathrm{~m}^{2} \mathrm{~s}^{-1}$ e $12,011 \times 10^{-11} \mathrm{~m}^{2} \mathrm{~s}^{-1}$ para as temperaturas de 30,40 e $50{ }^{\circ} \mathrm{C}$, respectivamente. Ao secar feijão nas temperaturas de 35 e $45{ }^{\circ} \mathrm{C}$ Resende et al. (2008) verificaram valores de 2,41 a $4,83 \times 10^{-9}$ $\mathrm{m}^{2} \mathrm{~s}^{-1}$ para o feijão vermelho e de 1,39 a $1,53 \times 10^{-9}$ $\mathrm{m}^{2} \mathrm{~s}^{-1}$ para o feijão preto. Ainda, Park et al. (2001) secaram a pera bartlett na faixa de temperatura de 50 a $70{ }^{\circ} \mathrm{C}$ e constataram o aumento dos valores do coeficiente de difusão, conforme a elevação da temperatura do ar de secagem, apresentando resultados entre $5,564 \times 10^{-9}$ e $1,370 \times 10^{-8} \mathrm{~m}^{2} \mathrm{~s}^{-1}$.

Com relação a variação do coeficiente de difusão efetivo verificou-se durante a secagem o aumento linear do coeficiente de difusão com a elevação da temperatura (Figura 3), estando em concordância com os resultados obtidos por Costa et al. (2011), no qual obtiveram aumento do coeficiente de difusão efetivo apresentando valores de $0,88 \times 10^{-11}$, $1,99 \times 10^{-11}, 2,90 \times 10^{-11}, 3,48 \times 10^{-11}$ e $5,85 \times 10^{-11}$ $\mathrm{m}^{2} \mathrm{~s}^{-1}$ para as temperaturas de $30,40,50,60$ e $70{ }^{\circ} \mathrm{C}$, respectivamente, durante a secagem do crambe.

Os valores do coeficiente de difusão efetivo aumentaram linearmente, corroborando com os resultados relatados por Costa et al. (2011) e Resende et al. (2010). A Figura 4 apresenta os valores de $D_{\text {ef }}$ na forma de "In $\mathrm{D}_{\mathrm{ef}}$ " descritos em função do recíproco da temperatura absoluta $\left(\mathrm{T}^{-1}\right)$, sua dependência com relação à temperatura do ar de secagem foi descrita pela equação de Arrhenius. O ajuste linear obtido indica que houve uniformidade na variação da difusividade com a temperatura (Reis et al., 2011), sendo o valor da variação do coeficiente de difusividade obtido a $50{ }^{\circ} \mathrm{C}$, um pouco superior em relação às temperaturas de 30 e $40{ }^{\circ} \mathrm{C}$, fato explicado em razão da vibração molecular de água, que segundo Goneli (2007) a variação do coeficiente de difusão efetivo se dá com a elevação da temperatura, o que aumenta o nível de vibração molecular das moléculas de água, contribuindo para uma difusão mais rápida. 


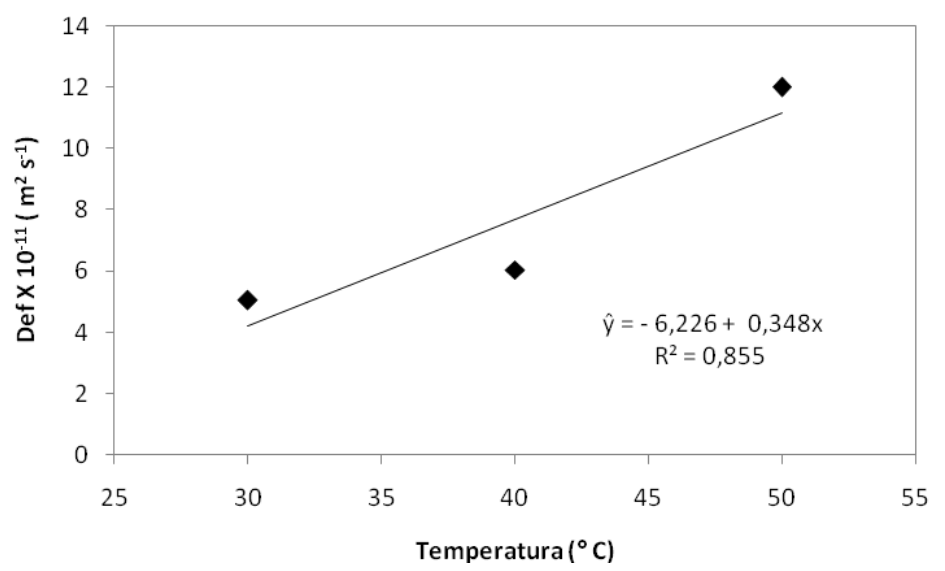

Figura 3. Valores do coeficiente de difusão $\left(\mathrm{m}^{2} \mathrm{~s}^{-1}\right)$ obtidos para a secagem do feijão-caupi (Vigna unguiculata (L.) Walp.) nas temperaturas de 30,40 e $50{ }^{\circ} \mathrm{C}$.

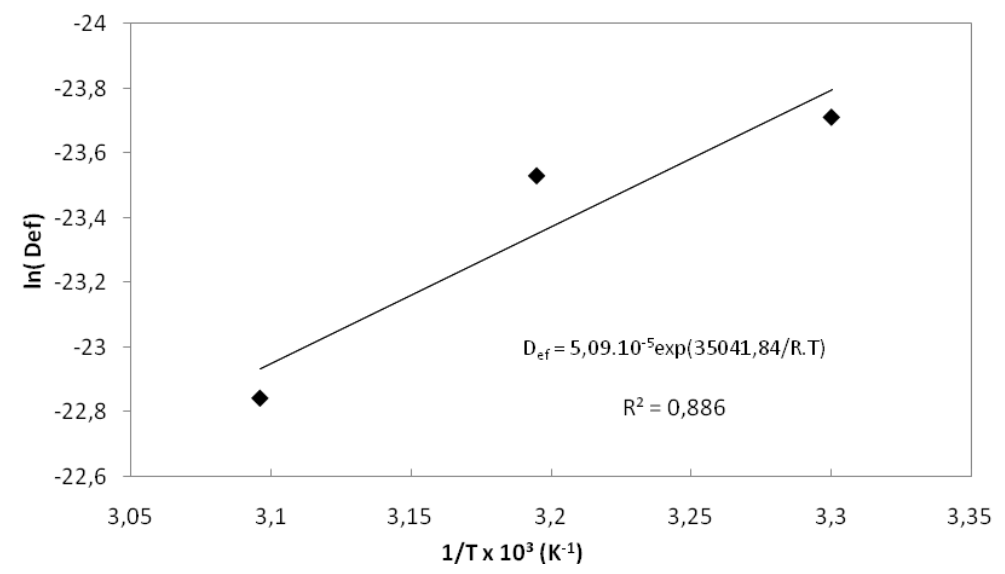

Figura 4. Representação de Arrhenius para o coeficiente de difusão em função da temperatura do ar de secagem obtido durante a secagem do feijão-caupi (Vigna unguiculata (L.) Walp.).

A inclinação da curva de representação de Arrhenius fornece a relação $E_{a} R^{-1}$, enquanto sua interseção com o eixo das ordenadas indica o valor de A. Na Eq. 19 estão apresentados os coeficientes da expressão de Arrhenius ajustada para os coeficientes de difusão efetivo do feijão-caupi.

Conforme observado, a energia de ativação para a difusão líquida no processo de secagem do feijão-caupi foi de $35,04 \mathrm{~kJ} \mathrm{~mol}^{-1}$. Nos processos de secagem quanto menor a energia de ativação maior será a difusividade de água no produto (Reis et al., 2011), e a energia de ativação é o valor mínimo necessário para que o processo de difusão ocorra.

Os valores encontrados estão próximos aos encontrados na secagem de outras variedades de feijão, bem como outros produtos agrícolas. Em trabalho desenvolvido por Corrêa et al. (2007) avaliando a secagem de feijão em camadas delgadas a temperaturas de 35,45 e $55^{\circ} \mathrm{C}$ os referidos autores verificaram que o produto apresentou energia de ativação para a difusão líquida de $10,08 \mathrm{~kJ} \mathrm{~mol}^{-1}$. Já Costa et al. (2011) ao secarem sementes de crambe para as temperaturas variando de 30 a $70{ }^{\circ} \mathrm{C}$ concluíram que o produto apresenta uma energia de ativação para a difusão líquida na secagem de $37,07 \mathrm{~kJ} \mathrm{~mol}^{-1}$.

\section{CONCLUSÕES}

O tempo necessário para a secagem de sementes de feijão-caupi até o teor de água de aproximadamente $11 \%$ (base úmida) é de 10,4, 5,6 e 2,1 horas para as temperaturas de 30,40 e $50{ }^{\circ} \mathrm{C}$, respectivamente.

O modelo matemático de Midilli foi o que melhor se ajustou aos dados experimentais nas diferentes condições de secagem.

O coeficiente de difusão aumentou com a elevação da temperatura, apresentando valores entre $5,047 \times 10^{-11}$ a $12,011 \times 10^{-11} \mathrm{~m}^{2} \mathrm{~s}^{-1}$ para a faixa de temperatura de 30 a $50{ }^{\circ} \mathrm{C}$.

A relação entre o coeficiente de difusão efetivo e a temperatura de secagem pode ser descrita pela equação de Arrhenius, a qual apresentou energia de ativação de $35,04 \mathrm{~kJ} \mathrm{~mol}^{-1}$ para a difusão líquida no processo de secagem das sementes de feijão-caupi.

\section{AGRADECIMENTOS}

À Coordenação de Aperfeiçoamento de Pessoal de Nível Superior (CAPES) pela concessão da 
bolsa ao primeiro autor e pelo apoio financeiro, essencial para o desenvolvimento deste trabalho.

\section{REFERÊNCIAS}

AFONSO JÚNIOR, P. C.; CORRÊA, P. C. Comparação de modelos matemáticos para descrição da cinética de secagem em camada fina de sementes de feijão. Revista Brasileira de Engenharia agrícola e ambiental, Campina Grande, v. 3, n. 3, p. 349-353, 1999.

AKPINAR, E. K.; BICER, Y.; YILDIZ, C. Thin layer drying of red pepper. Journal of Food Engineering, London,v. 59, n.1, p. 99-104, 2003.

AZZOUZ, S. et al. Moisture diffusivity and drying kinetic equation of convective drying of grapes. Journal of Food Engineering, London, v. 55, n. 4, p. 323-330, 2002.

BASUNIA, M. A., ABE, T. Moisture desorption isotherms of medium-grain rough rice. Journal of Stored Products Research, Amsterdam,v. 37, n. 3, p. 205-219, 2001.

BERBET, P. A. et al. Simulation of coffee drying in a fixed bed with periodic airflow reversal. Journal of Agricultural Engineering Research, London, v. 60, n. 3, p. 167-173, 1995.

BRASIL.Ministério da Agricultura, Pecuária e Abastecimento.Regras para análise de sementes. Brasília: SNDA/DNDV/CLAV, 2009. 395 p.

BORÉM, A.; CARNEIRO, J. E. S. A cultura. Revista Brasileira de Armazenamento, Viçosa, v. 35, n. 2, p. 15-18, 2006.

BROOKER, D. B.; BAKKER-ARKEMA, F. W.; HALL, C. W. Drying and Storage of Grains and Oilseeds. Westport: The AVI Publishing Company, 1992. $450 \mathrm{p}$.

CORRÊA, P. C. et al. Modelagem matemática para a descrição do processo de secagem do feijão (Phaseolus vulgaris L.) em camadas delgadas. Revista de Engenharia Agrícola, Jaboticabal, v. 27, n. 2, p. 501-510, 2007.

COSTA, L. M. et al. Coeficiente de difusão efetivo e modelagem matemática da secagem de sementes de crambe. Revista Brasileira de Engenharia Agrícola e Ambiental, Campina Grande, v. 15, n. 10, p. 1089-1096, 2011.

DIÓGENES, A. M. G. et al. Cinética de secagem de grãos de abóbora. Revista Caatinga, Mossoró, v. 26, n. 1, p. 71-80, 2013.
DOYMAZ, I. Drying kinetics of white mulberry. Journal of Food Engineering. Netherlands, v. 61, n. 3, p. 341-346, 2004.

FREIRE FILHO, F. R. et al.Feijão-caupi no Brasil: produção, melhoramento genético, avanços e desafios. Teresina: Embrapa Meio-Norte, 2011. 84 p.

GONELI, A. L. D. et al.Cinética de secagem de folhas de erva baleeira (CordiaverbenáceaDC.).Revista Brasileira de Plantas Medicinais, Campinas, v. 16, n. 2, p.434443, 2014.

GONELI, A. L. D. et al. Study of moisture diffusion in wheat grain drying. Ciência e Tecnologia de Alimentos, Campinas, v. 27, n. 1, p. 135-140, 2007.

GOYALDE, N. A. et al.Matemathical Modeling of the drying kinetics of sugarcane slices. Revista Brasileira de Produtos Agroindustriais, Campina Grande, v. 11, n. 2, p.117-121, 2009.

INSTITUTO BRASILEIRO DE GEOGRAFIA E ESTATÍSTICA - IBGE. Base Pública de Dados. Caderno estatístico do município de Capanema, 2012, p 01-40. Disponível em : <http:// www.educadores.diaadia.pr.gov.br/arquivos/File/ cadernos_municipios/capanema2012.pdf $>$, acesso 6 de abril de 2013.

KAYMAK-ERTEKIN, F. Drying and rehydrating kinetics of green and red peppers. Journal of Food Science, London, v. 67, n. 1, p. 168-175, 2002.

MADAMBA, P. S.; DRISCOLL, R. H.; BUCKLE, K. A. Thin layer drying characteristics of garlic slices. Journal of Food Engineering, Netherlands, v. 29, n.1, p. 75-97, 1996.

MARTINAZZO, A. P. et al. Análise e descrição matemática da cinética de secagem de folhas de capim-limão. Revista Brasileira de Engenharia Agrícola e Ambiental, Campina Grande, v. 11, n. 3, p. 301-306, 2007.

MENEGHETT, V. L. et al.Modelos matemáticos para a secagem intermitente de arroz em casca. Revista Brasileira de Engenharia Agrícola e Ambiental, Campina Grande, v. 16, n. 10, p. 1115-1120, 2012.

MOHAPATRA, D.; RAO, P. S. A thin layer drying model of parboiled wheat. Journal of Food Engineering, London, v. 66, n. 4, p. 513-518, 2005.

MORAIS, S. J. S. Cinética de secagem de grãos de feijão-caupi (Vigna unguiculata (L.) Walp.). 2010. 74 f. Dissertação (Mestrado em Engenharia Agrícola) - Universidade Estadual de Goiás, Anápolis, 2010 . 
PARK, K. J.; VOHNIKOZA, Z.; BROD, F. P. R. Evaluation of drying parameters and desorption isotherms of garden mint leaves (Mentha crispa L.). Journal of Food Engineering,London, v. 51, n. 3, p. 193-199, 2002.

PARK, K. J.; YADO, M. K. M; BROD, F. P. R. Estudo de secagem de pêra bartlett (Pyrus sp) em fatias. Ciência e Tecnologia de Alimentos, Campinas, v. 21, n. 3, p. 288-292, 2001.

REIS, R. C. et al. Modelagem matemática da secagem da pimenta cumari do Pará. Revista Brasileira de Engenharia Agrícola e Ambiental, Campina Grande, v. 15, n. 4, p. 347-353, 2011.

REIS, R.C. et al. Cinética de secagem de folhas de manjericão (Ocimum basilicum L.) via infravermelho. Revista Brasileira de Engenharia Agrícola e Ambiental, Campina Grande, v. 16, n. 12, p. 13461352, 2012.

RESENDE, O.; FERREIRA, L. U.; ALMEIDA, D. P. Modelagem matemática para descrição da cinética de secagem do feijão-adzuki (Vigna angularis). Revista Brasileira de Produtos Agroindustriais, Campina Grande, v. 12, n. 2, p. 171-178, 2010.

RESENDE, O. et al. Modelagem matemática do processo de secagem de duas variedades de feijão (Phaseolus vulgaris L.). Revista Brasileira de Produtos Agroindustriais, Campina Grande, v. 10, n. 1, p. 17-26, 2008.

RESENDE, O. et al. Contração volumétrica na infusão líquida durante o processo de secagem do arroz em casca. Revista Brasileira de Armazenamento, Viçosa, v. 30, n. 2, p. 163-171, 2005

ROMERO-PEÑA, L. M.; KIECKBUSCH, T. G. Influência de condições de secagem na qualidade de fatias de tomate. Brazilian Journal of Food Technology, Campinas, v. 6, n. 1, p. 69-76, 2003.

SANTOS, D. C. et al. Cinética de secagem de farinha de grãos residuais de urucum. Revista Brasileira de Engenharia Agrícola e Ambiental, Campina Grande, v. 17, n. 2, p. 223-231, 2013.

SIQUEIRA, V. C.; RESENDE, O.; CHAVES, T. H. Mathematical modelling of the drying of jatropha fruit: na empirical comparison. Revista Ciência Agronômica, Fortaleza, v. 44, n. 2, p. 278-285, 2013.

YALDIZ, O.; ERTEKIN,C.; UZUN, H. I. Mathematical modeling of thin layer solar drying of sultana grapes. Energy, v. 26, n. 5, p. 457-465, 2001. 